\title{
Medicare Expenditures for Nursing Home Residents Triaged to Nursing Home or Hospital for Acute Infection
}

\author{
Kenneth S. Boockvar, MD, MS ${ }^{*}$, Ann L. Gruber-Baldini, $\mathrm{PhD}^{\dagger}$, Bruce Stuart, PhD $\ddagger$, Sheryl \\ Zimmerman, $\mathrm{PhD} \S$, and Jay Magaziner, $\mathrm{PhD}^{\dagger}$
}

*Geriatric Research, Education, and Clinical Center, J.J. Peters Veterans Affairs Medical Center, Bronx, New York ${ }^{\dagger}$ Department of Epidemiology and Preventive Medicine, School of Medicine, University of Maryland, Baltimore, Maryland $¥$ School of Pharmacy, University of Maryland, Baltimore, Maryland ${ }^{\S}$ Cecil G. Sheps Center for Health Services Research and School of Social Work, University of North Carolina, Chapel Hill, North Carolina.

\section{Abstract \\ OBJECTIVES-To compare Medicare payments of nursing home residents triaged to nursing home with those of nursing home residents triaged to the hospital for acute infection care.}

DESIGN-Observational study with propensity score matching.

SETTING-Fifty-nine nursing homes in Maryland.

PARTICIPANTS-Two thousand two hundred eighty-five individuals admitted to the 59 nursing homes and followed between 1992 and 1997.

MEASUREMENTS—Demographic and clinical data were obtained from interviews and medical record review and linked to Medicare payment records. Incident infection was ascertained according to medical record review for new infectious diagnoses or prescription of antibiotics. Hospital triage was defined as hospital transfer within 3 days of infection onset. Hospital triage patients were paired with similar nursing home triage patients using propensity score matching. Medicare expenditures for triage groups were compared in 1997 dollars.

RESULTS-Of 3,618 infection cases, 28\% were genitouri-nary infections, 20\% skin, $14 \%$ upper respiratory, $12 \%$ lower respiratory, $4 \%$ gastrointestinal, and $2 \%$ bloodstream. Two hundred fiftysix pairs of hospital and nursing home triage cases fulfilled matching criteria. Mean Medicare payments \pm standard deviation were $\$ 5,202 \pm 7,310$ and $\$ 996 \pm 2,475$ per case in the hospital and nursing home triage groups, respectively, for a mean difference of $\$ 4,206$ (95\% confidence interval $=\$ 3,260-5,151)$. Mean payments per case in the hospital triage group were $\$ 3,628$ higher in inpatient expenditures, $\$ 482$ higher in physician visit expenditures, $\$ 161$ higher in emergency department expenditures, and $\$ 147$ higher in skilled nursing day expenditures.

CONCLUSION—Per-case Medicare expenditures are higher with hospital triage than for nursing home triage for nursing home residents with acute infection. This result may be used to estimate

(C) 2008, Copyright the AuthorsJournal compilation @ 2008 , No claim to original US government works

Address correspondence to Kenneth Boockvar, MD, MS, James J. Peters VA Medical Center, 130 West Kingsbridge Road, Bronx, NY 10468. kenneth.boockvar@mssm.edu.

Author Contributions: Boockvar: study concept and design, analysis and interpretation of data, preparation of manuscript. GruberBaldini, Stuart, Zimmerman, and Magaziner: study concept and design, acquisition of subjects and data, analysis and interpretation of data, preparation of manuscript. 
cost savings to Medicare of interventions designed to reduce hospital use by nursing home residents.

\section{Keywords}

infection; nursing homes; health expenditures; Medicare

Nursing home residents with acute infection who are treated in the nursing home have similar or better survival and fewer complications (e.g., pressure ulcers) than those who are treated in the hospital. ${ }^{1-5}$ From the societal perspective, hospitalization costs for nursing home residents with an acute infection exceed costs of care for treating the same condition in the nursing home ${ }^{3,6,7}$ although reducing hospital use is not necessarily financially beneficial to nursing homes, hospitals, or other providers. Of stake-holders, payers such as Medicare that are at risk for paying for hospital care have the strongest incentive to sponsor programs to reduce hospital use, providing rationale for a cost comparison of hospital and nursing home triage for care of acute infection in a nursing home resident from a payer's perspective. This comparison is important in light of Medicare's new Nursing Home ValueBased Demonstration (pay for performance), in which one of the measures used to determine nursing homes' financial reward is reduction in rate of potentially avoidable hospitalizations (including for pneumonia and urinary tract infection) and in which the financial incentive pool is generated from Medicare savings from reduced hospital use. ${ }^{8}$

Programs demonstrated to be effective in reducing nursing home residents' hospital use include placement of advanced practice nurses or physician assistants in the nursing home to provide acute illness care, ${ }^{9,10}$ decision-support guidelines to reduce inappropriate hospital transfers ${ }^{5}$ programs to inform residents and families about the option of hospice enrollment in the nursing home, ${ }^{11}$ and programs that provide financial incentives to keep nursing home residents out of the hospital (e.g., Evercare, Program of All-Inclusive Care for Elderly, managed care programs, pay for performance). Medicare has sponsored some of these programs, some of which have features of care management programs. Given that, according to the law, Medicare may require that a program or demonstration be not simply cost effective, but cost neutral, ${ }^{12}$ Medicare and providers considering implementing a program under agreement with Medicare require an accurate estimation of cost savings associated with substitution of nursing home care for hospital care.

The objective of this study was to compare Medicare payments between nursing home residents triaged to nursing home or hospital for acute infection care, using data from the Maryland Long-Term Care Project, an observational cohort of newly admitted nursing home residents. ${ }^{13}$ The perspective is that of the payer, who might develop or sponsor a program to reduce hospital use and who would reap some or all of the potential cost savings of such programs. Propensity scores were used to match individuals with similar risk profiles but different triage decisions, and matches were identified within the same nursing home to eliminate a comparison between sites that might have different technical resources or practice patterns. Based on the findings, what interventions to reduce hospital use of nursing home residents are likely to be cost saving to Medicare or other stakeholders are discussed.

\section{METHODS}

Patients

The design of the Maryland Long-Term Care Project has been described previously. ${ }^{13,14}$ All 221 licensed long-term care facilities in Maryland were grouped into 15 strata according to geographic region (5 strata) and bed size $(<50,50-150,>150)$, and facilities within each stratum were selected using weighted random sampling. Of 64 selected facilities, 60 agreed 
to participate; one reported no new admissions during the study period, leaving 59 facilities in the study. All individuals admitted to one of these facilities between September 1992 and March 1995 who were aged 65 and older and had not resided in a nursing home or chronic care facility for 8 or more days in the previous year and for whom timely baseline data could be collected were eligible to be enrolled. Of 3,283 individuals, 2,285 individuals or their surrogates (70\%) gave written informed consent. New residents and their family members and staff caregivers were interviewed at the time of admission, and the residents' nursing home chart was abstracted. Individuals were followed using medical record review until nursing home discharge or 2 years after nursing home admission. The human subjects committee at the University of Maryland, Baltimore, approved the study protocol.

\section{MEASURES}

\section{Infection Cases and Characteristics}

Incident infection was defined as documentation of an infectious diagnosis in any part of the medical record, including nursing notes, physician notes, orders, consults, and outside medical reports, or receipt of antibiotics except if prescribed the day preceding, day of, or day after a surgical procedure or if prescribed chronically for infection prophylaxis. The onset date was defined as the date the infection was first documented in the chart or the date antibiotics were first ordered, whichever occurred earlier. The end date was defined as the date of documentation of infection resolution or the last date of receipt of antibiotics, whichever occurred later. More than one infection case could occur in an individual as long as a new case started at least 30 days after the start date of a previous case or, if the previous case lasted longer than 30 days, 7 days after the previous case's end date, to obtain a minimum spacing of one infection per month. Of 3,618 infections that occurred, 3,138 had end dates; the 480 (13.3\%) with missing end dates were assigned a 30-day duration.

Infection site was classified as gastrointestinal, genitourinary, lower respiratory, skin, bloodstream, upper respiratory, other, or undetermined. Eye, gynecological, and toenail infections were excluded because of the absence of hospital transfers for these types. Temperature (highest measured in 5 categories: $<100.0^{\circ} \mathrm{F}, 100.0-100.9^{\circ} \mathrm{F}, 101.0-101.9^{\circ} \mathrm{F}$, $102.0-102.9^{\circ} \mathrm{F}$, and $\geq 103.0^{\circ} \mathrm{F}$ ) and physician visits within 3 days of infection onset were recorded.

\section{Hospital Versus Nursing Home Triage and Clinical Outcomes}

Variation in triage decisions occurred as part of usual care. Cases were assigned based on whether patients were transferred to the hospital or emergency department within 3 days of infection onset. To approximate the intention-to-treat principle, patients transferred to the emergency department within 3 days of infection onset were assigned to the hospital triage group whether or not they were admitted to the hospital from the emergency department. Patients who remained in the nursing home for the first 3 days of infection were assigned to the nursing home triage group whether or not they subsequently remained in the nursing home. Residents who died within 3 days of infection onset were not assigned to a group and were excluded from analyses.

\section{Medicare Payments}

Medicare payment records from between 1992 and 1997 were obtained for study participants. Medicare records could be matched for 2,074 (90.8\%) of the 2,285 study individuals. Only payments made to healthcare providers were counted, and beneficiary cost-sharing amounts were not included. The date of service information on each bill record was used to assign payments to an infection case. Payments that occurred between infection start and end dates were summed to determine the total case cost. Payments were 
categorized according to location (nursing home, emergency department, inpatient hospital), and type (provider, diagnostic procedure, treatment, and Medicare skilled nursing days). Costs were inflated to constant December 1997 dollars using the Consumer Price Index, Medical Care subindex.

\section{Patient Characteristics}

Age, sex, race, education, weight, height, Medicaid eligibility, Medicare qualified stay status, and hospital use in the past year were recorded upon admission to the nursing home. A geriatric psychiatrist and neurologist examined all interview and medical record data to determine dementia status, using Diagnostic and Statistical Manual of Mental Disorders, Third Edition, Revised, criteria. ${ }^{13,15}$ The presence of a pressure ulcer at nursing home admission was recorded. A count of 14 conditions (coronary artery disease, congestive heart failure, cerebrovascular disease, chronic obstructive pulmonary disease, arthritis, cancer, diabetes mellitus, malnutrition, uncontrolled hypertension, liver disease, peripheral vascular disease, seizure disorder, pressure ulcer, and dementia) as ascertained according to interview with patient, family member, or caregiver was calculated as a measure of chronic illness burden. Medicare payments in the year before nursing home admission were used to calculate the Diagnostic Cost Group/Hierarchical Coexisting Condition (DCG/HCC) score, which represents the patient's predicted Medicare expenditures in the following year. ${ }^{16} \mathrm{~A}$ score for function in six activities of daily living (ADLs; bathing, dressing, toileting, transferring, feeding, and continence) was calculated from the nursing home Minimum Data Set (MDS), using the MDS ADL "long form."17

\section{Nursing Home Characteristics}

Facility bedsize, proprietary status, rural versus urban location, ${ }^{18}$ distance to hospital (0-5 vs $\ 6$ miles), and nurse staffing (number of full-time equivalent registered nurses and licensed practical nurses per 100 beds) were obtained from administrative forms and from interviews with nursing home administrators.

\section{Analyses}

Propensity scores were used to match individuals with similar risk profiles but different triage decisions, and matches within the same nursing home were identified to avoid comparing patients from different sites that might have different technical resources or practice approaches for taking care of acutely ill residents. To generate a propensity score for each case, a multivariable regression model was first estimated in which triage group was the dependent variable, and infection and patient characteristics were the independent variables, using all 3,618 infection cases. ${ }^{19}$ Generalized estimating equations (GEEs) ${ }^{20}$ were used to estimate a generalized model with a binomial distribution, a logit link function, and a robust variance estimate that adjusted for within-facility and within-individual correlation. ${ }^{21}$ Regression coefficients were estimated for site of infection, highest temperature, physician visit within 3 days of infection onset, age, sex, race, education, ADL function, chronic medical conditions, pressure sore at baseline, body mass index, dementia status, hospitalization in the past year, DCG/HCC score, Medicaid eligibility, and Medicare qualified stay status. Body mass index was missing in 224 of 3,618 (6.1\%) cases and was imputed as the mean sample value. The model's c statistic, a measure of discrimination, was 0.71 ( $c$ ranges from 0.5 to 1.0 , with 1.0 representing perfect discrimination and 0.5 representing no better than random discrimination). ${ }^{22}$

A propensity score was generated by multiplying the model's regression coefficients with each case's observed values and then summing the products. It was then attempted to match each case of actual hospital triage ( $n=273,7.5 \%$ of all cases) with a case of nursing home triage from the same nursing home within a propensity score caliper of 0.06 (which equals 
0.08 times the standard deviation of the logit propensity score), using Mahalanobis distance matching. ${ }^{23}$ It was possible to identify 256 matched pairs $(94 \%)$ that fulfilled these criteria, resulting in an analytical sample of 512. Group balance was tested by calculating $P$-values for differences in covariates between the triage groups, using $t$-tests for continuous variables and chi-square tests for percentages. The standardized difference was also calculated for each covariate. A standardized difference less than 0.10 indicates adequate balance. ${ }^{24}$

Cost differences between triage groups were calculated. A regression model was estimated in which the key independent variable was triage group, the dependent variable was cost per case, and covariates were variables not adequately balanced by the matching procedure (standardized difference $>0.10$ ), using GEE and a robust variance estimate. A gamma distribution was used for costs, ${ }^{25}$ and a cost ratio (hospital:nursing home triage) with $95 \%$ confidence intervals was calculated. To test the effect of assigned infection duration on payments, sensitivity analyses were performed in which Medicare payments for 14 days rather than 30 days after infection onset were included for the following subsamples: first only for cases missing an infection end date and second for cases missing an infection end date or that were longer than 14 days. In addition, for cases that had Medicare skilled nursing payments, a sensitivity analysis was performed in which such payments were included only in cases in which they began at the time of infection onset or after (suggesting that the infection precipitated the skilled nursing payments), instead of in all cases. All analyses were performed with STATA v. 8 (Stata Corp., College Station, TX), using xtgee, pscore, ${ }^{26}$ and psmatch $^{2,23}$ procedures.

\section{RESULTS}

\section{Setting}

Study nursing homes had a mean capacity of $146.2 \pm 77.1$ beds. Thirty-five $(59 \%)$ were for profit, $53(90 \%)$ were located in an urban setting, and $41(70 \%)$ were 5 miles or less from a hospital.

\section{Infection Cases}

Study nursing home residents had a total of 3,618 infections, of which $28 \%$ were genitourinary, $20 \%$ skin, $14 \%$ upper respiratory, $12 \%$ lower respiratory, $4 \%$ gastrointestinal, and $2 \%$ bloodstream (Table 1). Hospital triage before infection day 3 occurred in 273 cases $(7.5 \%)$ and in general was associated with more-severe illness and worse health status. Variables associated with hospital triage were lower respiratory tract infection site (odds ratio $(\mathrm{OR})=1.94, P<.001)$, bloodstream site $(\mathrm{OR}=1.92, P=.001)$, higher temperature $(\mathrm{OR}$ $=1.18, P<.001)$, more chronic conditions $(\mathrm{OR}=1.05, P=.02)$, lower body mass index $(\mathrm{OR}$ $=0.99, P=.034)$, higher DCG/HCC score $(\mathrm{OR}=1.01, P=.001)$, and less education $(\mathrm{OR}=$ $0.97, P=.002$ ) (Table 1).

Propensity score matching resulted in an analytical sample of hospital and nursing home triage comparison groups $(\mathrm{n}=256$ in each) that were well matched. They were not statistically different $(P>.05)$ in any baseline characteristic, including demographics, cognitive and physical function, and infection characteristics (Table 2), and only race, education, Medicaid eligibility, and DCG/HCC score exceeded a 0.10 level in standardized difference.

\section{Hospital Versus Nursing Home Triage Comparison}

Mean Medicare payments were \$5,202 \pm 7,310 and $\$ 996 \pm 2,475$ per infection case in the hospital and nursing home triage groups, respectively, for a mean difference of $\$ 4,206(95 \%$ confidence interval $(\mathrm{CI})=\$ 3,260-5,151$, median $\$ 1,476$, interquartile range $\$ 295-6,757$ ) 
(Table 3). Mean expenditures per case in the hospital triage group were $\$ 3,628$ (95\% CI = \$2,730-4,526) higher in inpatient payments, \$161 (95\% CI = \$136-186) higher in emergency department payments, $\$ 147(95 \% \mathrm{CI}=\$ 48-245)$ higher in nursing home skilled nursing payments, and $\$ 482(95 \% \mathrm{CI}=\$ 338-626)$ higher in physician visit payments. Using a robust variance estimate that accounted for clustering of observations within individuals and facilities, the hospital:nursing home Medicare payment ratio was 6.07 (95\% $\mathrm{CI}=4.30-8.58, P<.001$ ) (Table 3 ).

\section{Sensitivity Analyses}

Mean total Medicare payments were $\$ 3,461$ higher in the hospital triage group when Medicare payments were included for 14 days instead of 30 days in cases missing an infection end date. They were $\$ 3,393$ higher when Medicare payments were included for 14 days instead of 30 days in cases missing an infection end date or that were longer than 14 days. Finally, they were $\$ 4,149$ higher when nursing home skilled nursing payments were included only in cases in which skilled nursing days began at the time of infection onset or after instead of in all cases. Hospital:nursing home payment ratios in each sensitivity analysis were similar to the base case analysis, ranging from 6.2 to 6.8 .

\section{DISCUSSION}

In this study, mean Medicare payments for care of acute infection in nursing home residents were $\$ 5,202$ and $\$ 996$ with hospital and nursing home triage, respectively, for a per case difference of \$4,206 in 1997 dollars. Inflated to December 2006 dollars using the Consumer Price Index Medical Care subindex, ${ }^{27}$ the per-case difference was $\$ 6,033$. The smallest percase difference that was observed in sensitivity analyses was $\$ 3,393$ (in 1997 dollars; $\$ 4,867$ in 2006 dollars). Therefore, interventions designed to substitute nursing home triage for hospital triage that cost less than $\$ 4,867$ per case are likely to be cost saving to Medicare. For example, in the Evercare model, a nurse practitioner that provided "intensive service" for acutely ill nursing home residents reduced hospital use by 24.7 hospital admissions per 85 patients per year (the average nurse practitioner caseload). ${ }^{7}$ This model would reduce annual Medicare payments by between $\$ 120,214$ and $\$ 149,015$ and, with annual nurse practitioner salary and benefits of approximately $\$ 100,000$ in 2006 , would likely result in overall savings. In contrast, a hospice eligibility assessment intervention for nursing home residents that reduced 6-month hospital use by 21 hospital admissions per 100 patients did this by increasing Medicare hospice enrollment. The higher Medicare hospice payments, which were estimated to be $\$ 213,720$ (1,644 more Medicare hospice days at $\$ 130 /$ day), ${ }^{28}$ would exceed the lower 6-month Medicare payments of between \$102,207 and \$126,693 associated with this intervention.

The observed Medicare payment difference between hospital and nursing home triage for nursing home residents with infection exceeded cost differences estimated in other studies. This study's hospital:nursing home triage payment ratio of 6.07 per case was higher than that estimated in a study of care for pneumonia in which patients hospitalized within 24 hours of evaluation had 2.75 times higher costs than those who were not $(\$ 10,408$ per case for initial hospital treatment vs $\$ 3,789$ for initial nursing home treatment), ${ }^{3}$ although that study included nursing home custodial care costs, which were not included in the current study. Similarly, a study in Ontario in which a study nurse triaged nursing home residents with lower respiratory infection to nursing home or hospital care based on clinical pathway criteria reduced absolute hospitalization rates $12 \%$, with overall estimated U.S. cost savings of $\$ 1,517$ per case in the intervention group and a hospital:nursing home triage cost ratio of $1.86 .{ }^{5}$ Finally, a study of nursing home residents in New York State between 1999 and 2004 found average hospitalization costs of $\$ 11,252, \$ 9,354$, and $\$ 9,067$ for pneumonia, kidney or urinary tract infection, and cellulitis, respectively, although costs were estimated from 
hospital charges, and there was no estimate of nursing home costs, prohibiting an estimate of cost savings. 29

A strength of the current study is that it takes a payer's perspective and uses payment data obtained from Medicare. The societal perspective may miss the fact that reducing hospital use is not necessarily financially beneficial to nursing homes, hospitals, or other providers when reimbursed by fee-for-service Medicare or other insurance. For nursing homes, acute illness care places temporary increased burden on nursing staff, a burden that payers might not compensate. For hospitals, reducing hospital use by nursing home residents may reduce revenue unless higher-revenue patients continually and fully occupy the hospital. Thus, of stakeholders, payers such as Medicare that are at risk for paying for hospital care have the strongest incentive to sponsor programs to reduce hospital use, providing rationale for a cost comparison of hospital versus nursing home triage from the payer's perspective.

An important limitation of this study is that patients in the hospital triage group probably had slightly more-severe infections on average than patients in the nursing home triage group, even with propensity matching. Unmeasured factors that may have contributed to this imbalance include blood pressure; heart rate; respiratory rate; mental status; and hematology, chemistry, and microbiology laboratory parameters. As a result, this analytical approach is not meant to suggest that all observed hospital triage was inappropriate or that all hospitalized patients could have been managed in the nursing home under circumstances existing at that time. Nevertheless, the approach identifies nursing home triage patients who were similar to hospital triage patients, suggesting that nursing home management might have been feasible. In addition, other studies have found that $40 \%$ of hospital admissions from nursing homes may be rated as inappropriate ${ }^{30}$ and that, in nursing home residents in New York State, 29\% of hospitalizations in 2004 were for "ambulatory care sensitive conditions" (i.e., might have been prevented with higher-quality care in the nursing home), of which the top two diagnoses, making up $51 \%$ of ambulatory-care-sensitive hospitalizations, were pneumonia and urinary tract infection. ${ }^{29}$

A second important limitation is the possibility that findings from clinical and payment data from 1992 to 1997 may not be applicable to current providers and payers. With regard to trends in clinical characteristics of nursing home residents, it has been suggested that nursing home residents now have greater levels of illness burden and severity. ${ }^{31}$ In this regard, it is worth noting that the analytical sample excluded nursing home triage cases that were of low severity and could not be matched to a hospital triage case; only those cases that were of a similar severity to hospitalized cases (the more severe) were included.

Consequently, it is likely that the analytical cases had a level of severity and poor health that exists in nursing homes today. Nevertheless, these methods resulted in only a fraction of the available data being used.

Two significant changes have occurred in Medicare payment since the study period. The first was the introduction of the prospective payment system for nursing home provision of skilled nursing services (e.g., rehabilitation) in 1998. However, payments for Medicare skilled nursing days made up a small fraction of the total infection payment amounts, which remains likely to be true today (Table 3 ). The second change was the implementation of Medicare coverage for prescription drugs in the nursing home (Medicare Part D). To address this, infection-related nursing home Medicaid drug expenditures of 185 matched pairs of dually eligible (Medicaid and Medicare) study participants were examined, and only a small difference was found between triage groups in this category (\$124 and \$171 in nursing home and hospital triage groups, respectively). 
A previous report using this sample suggests that clinical outcomes (mortality and pressure ulcer rates) are equal or better with nursing home triage for selected nursing home residents with infection. ${ }^{4}$ Other studies suggest that nursing home residents with pneumonia have equal or better outcomes with nursing home triage. ${ }^{1-3,5}$ Patients transferred to the hospital are exposed to greater risk of iatrogenic harm as a result of care handoffs ${ }^{32}$ and a moreinvasive approach in the hospital. ${ }^{33}$ An observational design limits each of these studies, and worse illness severity in the hospitalized group might confound the findings.

In conclusion, Medicare expenditures for managing infections in nursing home residents may be reduced with interventions that enable providers to manage these conditions safely and effectively in the nursing home in residents who would otherwise be transferred to an acute hospital. If interventions to reduce hospital triage involved increasing nurse or other staffing in the nursing home ${ }^{9,10}$ — staffing that has decreased since Medicare implemented prospective payment ${ }^{34}$ — the potential exists that residents would benefit from the improved staffing even when not acutely ill. Furthermore, interventions that increase attention to patients' do-not-hospitalize preferences or increase patients' access to palliative, hospice, and end-of-life care ${ }^{11}$ would address a pressing need of modern nursing facilities, which are increasingly recognized as an important site for end-of-life care. This study's comparison is also important in light of Medicare's new nursing home pay-for-performance demonstration, in which the financial incentive pool is generated from Medicare savings from reduced hospital use. ${ }^{8}$ The challenges of creating sensible management programs and better quality of care depend partly on creating rational financial incentives; whether pay-for-performance fulfills this need is currently an open question. ${ }^{35}$

\section{Acknowledgments}

The authors would like to acknowledge Van Doren Hsu, PharmD, of Pharmaceutical Research Computing, University of Maryland Baltimore for programming support and Daniel Gilden of Jen Associates for the MedicareMedicaid data merge and technical assistance with the files. We thank the Maryland Department of Health and Mental Hygiene for access to Medicaid data and the Centers for Medicare and Medicaid Services for access to Medicare data. We also acknowledge the cooperation of the facilities, residents, and families participating in the Maryland Long-Term Care Project. Other investigators in The Epidemiology of Dementia in Nursing Homes Research Group include: Lynda Burton, ScD, J. Richard Hebel, PhD, Steven Kittner, MD, MPH, Conrad May, MD, George Taler, MD, Verita Custis Buie, PhD, Charlene Quinn, PhD, RN, and Ilene Zuckerman, PharmD.

Conflict of Interest: This research was supported by grants from the National Institute on Aging (RO1 AG8211; R29 AG11407) and a Pfizer/Foundation for Health in Aging Junior Faculty Scholarship for Research on Health Outcomes in Geriatrics (to Dr. Boockvar). Dr. Boockvar is currently supported by VA Health Services Research and Development (RCD 03-027-1). Boockvar: financial support for research from Department of Veterans Affairs (no conflict). Gruber-Baldini: financial support from TEVA Pharma ceutical Industries and Welldoc Communications, Inc. for research unrelated to the research being reported. Magaziner: financial support from Novartis Pharmaceuticals, Merck and Co., Pfizer Pharmaceuticals, and Amgen Corporation for activities unrelated to the research being reported.

Sponsor's Role: Sponsors had no role in the design, methods, subject recruitment, data collection, analysis, or preparation of the manuscript.

\section{REFERENCES}

1. Fried T, Gillick M, Lipsitz L. Short-term functional outcomes of long-term care residents with pneumonia treated with and without hospital transfer. J Am Geriatr Soc. 1997; 45:302-306. [PubMed: 9063275]

2. Dosa D. Should I hospitalize my resident with nursing home-acquired pneumonia? J Am Med Dir Assoc. 2005; 6:327-333. [PubMed: 16165074]

3. Kruse RL, Mehr DR, Boles KE, et al. Does hospitalization impact survival after lower respiratory infection in nursing home residents? Med Care. 2004; 42:860-870. [PubMed: 15319611] 
4. Boockvar KS, Gruber-Baldini AL, Burton L, et al. Outcomes of infection in nursing home residents with and without early hospital transfer. J Am Geriatr Soc. 2005; 53:590-596. [PubMed: 15817003]

5. Loeb M, Carusone SC, Goeree R, et al. Effect of a clinical pathway to reduce hospitalizations in nursing home residents with pneumonia: A randomized controlled trial. JAMA. 2006; 295:25032510. [PubMed: 16757722]

6. Alessi C, Ouslander JG, Maldague S, et al. Incidence and costs of acute medical conditions in longstay incontinent nursing home residents. J Am Med Dir Assoc. 2002; 3:229-241. [PubMed: 12807643]

7. Kane RL, Keckhafer G, Flood S, et al. The effect of Evercare on hospital use. J Am Geriatr Soc. 2003; 51:1427-1434. [PubMed: 14511163]

8. White, A.; Hurd, D.; Moore, T., et al. Quality Monitoring for Medicare Global Payment Demonstrations: Nursing Home Quality-Based Purchasing Demonstration Final Design Report. Abt Associates Inc.; Cambridge, MA: 2006. [online]. Available at http://www.cms.hhs.gov/ DemoProjectsEvalRpts/downloads/NHP4P_FinalReport.pdf [December 10, 2007]

9. Kane RL, Huck S. The implementation of the EverCare demonstration project. J Am Geriatr Soc. 2000; 48:218-223. [PubMed: 10682954]

10. Ackermann RJ, Kemle KA. The effect of a physician assistant on the hospitalization of nursing home residents. J Am Geriatr Soc. 1998; 46:610-614. [PubMed: 9588375]

11. Casarett D, Karlawish J, Morales K, et al. Improving the use of hospice services in nursing homes: A randomized controlled trial. JAMA. 2005; 294:211-217. [PubMed: 16014595]

12. Department of Health and Human Services. Medicare program: Care management for high-cost beneficiaries demonstration. Fed Reg. 2004; 69:59929-59930.

13. Magaziner J, German P, Zimmerman SI, et al. The prevalence of dementia in a statewide sample of new nursing home admissions aged 65 and older: Diagnosis by expert panel. Epidemiology of dementia in nursing homes research group. Gerontologist. 2000; 40:663-672. [PubMed: 11131083]

14. Burton LC, German PS, Gruber-Baldini AL, et al. Medical care for nursing home residents: Differences by dementia status. Epidemiology of dementia in nursing homes research group. J Am Geriatr Soc. 2001; 49:142-147. [PubMed: 11207867]

15. Diagnostic and Statistical Manual of Mental Disorders, III-R. American Psychiatric Association; Washington, DC: 1987.

16. Pope GC, Kautter J, Ellis RP, et al. Risk adjustment of Medicare capitation payments using the CMS-HCC model. Health Care Financ Rev. 2004; 25:119-141. [PubMed: 15493448]

17. Morris JN, Fries BE, Morris SA. Scaling ADLs within the MDS. J Gerontol A Biol Sci Med Sci. 1999; 54A:M546-M553. [PubMed: 10619316]

18. Cohen SB, Braden JJ, Ward EP. Enhancing the representation of rural areas in the National Medical Expenditure Survey. J Rural Health. 1993; 9:188-203. [PubMed: 10128158]

19. Rubin DB. Estimating causal effects from large data sets using propensity scores. Ann Intern Med. 1997; 127:757-763. [PubMed: 9382394]

20. Liang KY, Zeger SL. Longitudinal data analysis using generalized linear models. Biometrika. 1986; 73:13-22.

21. Williams RL. A note on robust variance estimation for cluster-correlated data. Biometrics. 2000; 56:645-646. [PubMed: 10877330]

22. Ash, AS.; Schwartz, M. Evaluating the performance of risk-adjustment methods: Dichotomous outcomes.. In: Iezzoni, LI., editor. Risk Adjustment for Measuring Health Care Outcomes. Health Administration Press; Chicago: 1997.

23. Leuven, E.; Sianesi, B. [December 3, 2007] PSMATCH2: Stata module to perform full Mahalanobis and propensity score matching, common support graphing, and covariate imbalance testing. Statistical Software Components [on-line]. Available at http://ideas.repec.org/c/boc/ bocode/s432001.html

24. Normand ST, Landrum MB, Guadagnoli E, et al. Validating recommendations for coronary angiography following acute myocardial infarction in the elderly: A matched analysis using propensity scores. J Clin Epidemiol. 2001; 54:387-398. [PubMed: 11297888] 
25. Veazie PJ, Manning WG, Kane RL. Improving risk adjustment for Medicare capitated reimbursement using nonlinear models. Med Care. 2003; 41:741-752. [PubMed: 12773840]

26. Becker S, Ichino A. Estimation of average treatment effects based on propensity scores. Stata J. 2002; 2:358-377.

27. Bureau of Labor Statistics. [October 15, 2007] Consumer Price Indexes [on-line]. Available at http://www.bls.gov/cpi/

28. Centers for Medicare and Medicaid Services. [October 15, 2007] Correction to Annual Change in Medicaid Hospice Payment Rates 9on-line]. Available at http://www.cms.hhs.gov/

ProspMedicareFeeSvcPmtGen/downloads/medicaidhospicerates.pdf

29. Grabowski DC, O'Malley AJ, Barhydt NR. The costs and potential savings associated with nursing home hospitalizations. Health Aff (Millwood). 2007; 26:1753-1761. [PubMed: 17978395]

30. Saliba D, Kington R, Buchanan J, et al. Appropriateness of the decision to transfer nursing facility residents to the hospital. J Am Geriatr Soc. 2000; 48:154-163. [PubMed: 10682944]

31. Feng Z, Grabowski DC, Intrator O, et al. The effect of state Medicaid case-mix payment on nursing home resident acuity. Health Serv Res. 2006; 41:1317-1336. [PubMed: 16899009]

32. Coleman EA. Falling through the cracks: Challenges and opportunities for improving transitional care for persons with continuous complex care needs. J Am Geriatr Soc. 2003; 51:549-555. [PubMed: 12657078]

33. Steel K, Gertman PM, Crescenzi C, et al. Iatrogenic illness on a general medical service at a university hospital. N Engl J Med. 1981; 304:638-642. [PubMed: 7453741]

34. Konetzka RT, Norton EC, Sloane PD, et al. Medicare prospective payment and quality of care for long-stay nursing facility residents. Med Care. 2006; 44:270-276. [PubMed: 16501399]

35. Grabowski DC. Medicare and medicaid: Conflicting incentives for long-term care. Milbank Q. 2007; 85:579-610. [PubMed: 18070331] 
Table 1

Characteristics of Infection Cases in Nursing Home Residents $(\mathrm{N}=3,618)$ and Features Associated with Hospital Triage within 3 Days of Infection Onset

\begin{tabular}{|c|c|c|}
\hline Patient Characteristic & Value & $\begin{array}{l}\text { Multivariate Odds of Hospital Triage } \\
\text { (95\% Confidence Interval) }\end{array}$ \\
\hline Male, $\%$ & 27 & $0.97(0.84-1.12)$ \\
\hline Age, mean \pm SD & $82.1 \pm 7.3$ & $1.00(0.99-1.01)$ \\
\hline Caucasian, $\%$ & 80 & $0.95(0.81-1.11)$ \\
\hline Education, years, mean \pm SD & $10.2 \pm 3.6$ & $0.97(0.95-0.99) / /$ \\
\hline Minimum Data Set activity of daily living score, mean \pm SD & $19.5 \pm 9.5$ & $1.00(0.99-1.01)$ \\
\hline Number of chronic conditions, mean $\pm \mathrm{SD}$ & $2.6 \pm 1.6$ & $1.05(1.01-1.10)^{\mathcal{S}}$ \\
\hline Dementia, $\%$ & 57 & $0.88(0.77-1.01)$ \\
\hline Body mass index, $\mathrm{kg} / \mathrm{m}^{2}$, mean $\pm \mathrm{SD}$ & $23 \pm 5.4$ & $0.99(0.97-1.00)^{\mathcal{S}}$ \\
\hline Hospitalized within the past year, $\%$ & 81 & $1.06(0.88-1.29)$ \\
\hline Pressure ulcer at nursing home admission, $\%$ & 12 & $0.95(0.78-1.16)$ \\
\hline Medicaid eligible, $\%$ & 28 & $1.08(0.94-1.25)$ \\
\hline Diagnostic Cost Group/Hierarchical Coexisting Condition score, mean \pm SD & $13,972 \pm 8,569$ & $1.01(1.01-1.02)^{q /}$ \\
\hline Medicare qualifying stay, $\%$ & 45 & $0.94(0.82-1.09)$ \\
\hline \multicolumn{3}{|l|}{ Infection characteristics, $\%$} \\
\hline Genitourinary & 28 & $1.15(0.95-1.40)$ \\
\hline Skin & 20 & $1.03(0.82-1.28)$ \\
\hline Upper respiratory & 14 & $0.97(0.76-1.25)$ \\
\hline Lower respiratory & 12 & $1.94(1.57-2.39)^{\mathscr{I}}$ \\
\hline Gastrointestinal & 4 & $0.98(0.65-1.47)$ \\
\hline Bloodstream & 2 & $1.92(1.32-2.80)^{q /}$ \\
\hline Fever $>100.0^{\circ} \mathrm{F}$ & 11 & $1.18(1.10-1.25)^{q /}$ \\
\hline Physician visit within 3 days of infection onset & 37 & $0.94(0.82-1.07)$ \\
\hline \multicolumn{3}{|l|}{$\mathrm{SD}=$ standard deviation } \\
\hline \multicolumn{3}{|l|}{$\xi_{P<.05}$} \\
\hline \multicolumn{3}{|l|}{$/ / .01$} \\
\hline Il.001. & & \\
\hline
\end{tabular}


Table 2

Characteristics of Infection Cases in Nursing Home Residents Stratified According to Triage Group, After Matching According to Propensity Score $(n=256$ in Each Group)

\begin{tabular}{|c|c|c|c|c|}
\hline Patient Characteristic & Hospital Triage & Nursing Home Triage & $P$-Value & Standardized Difference \\
\hline Male, \% & 29 & 27 & .56 & 0.051 \\
\hline Age, mean \pm SD & $82.0 \pm 7.2$ & $82.4 \pm 7.4$ & .51 & -0.059 \\
\hline Caucasian, $\%$ & 74 & 67 & .08 & 0.154 \\
\hline Education, years, mean \pm SD & $9.5 \pm 3.4$ & $8.9 \pm 3.6$ & .06 & 0.171 \\
\hline $\begin{array}{l}\text { Minimum Data Set activity of daily living score, mean } \\
\pm \text { SD }\end{array}$ & $20.0 \pm 9.6$ & $20.1 \pm 9.7$ & .92 & -0.009 \\
\hline Chronic conditions, $\%$ & $2.9 \pm 1.6$ & $3.0 \pm 1.7$ & .92 & -0.012 \\
\hline Dementia, \% & 51 & 52 & .72 & -0.030 \\
\hline Body mass index, $\mathrm{kg} / \mathrm{m}^{2}$, mean $\pm \mathrm{SD}$ & $22.4 \pm 5.1$ & $22.3 \pm 5.3$ & .94 & 0.008 \\
\hline Hospitalized within past year, $\%$ & 86 & 87 & .90 & -0.012 \\
\hline Pressure ulcer at nursing home admission, $\%$ & 13 & 13 & .79 & -0.024 \\
\hline Medicaid eligible, $\%$ & 33 & 39 & .17 & -0.123 \\
\hline $\begin{array}{l}\text { Diagnostic Cost Group/Hierarchical Coexisting } \\
\text { Condition score, mean } \pm \text { SD }\end{array}$ & $16,409 \pm 9,808$ & $17,672 \pm 10,250$ & .20 & -0.126 \\
\hline Medicare qualifying stay, $\%$ & 47 & 48 & .93 & -0.008 \\
\hline \multicolumn{5}{|l|}{ Infection characteristics, $\%$} \\
\hline Genitourinary & 28 & 29 & .77 & -0.027 \\
\hline Skin & 14 & 15 & .90 & -0.008 \\
\hline Upper respiratory & 10 & 11 & .57 & -0.022 \\
\hline Lower respiratory & 25 & 22 & .35 & 0.083 \\
\hline Gastrointestinal & 2 & 1 & .31 & 0.089 \\
\hline Bloodstream & 5 & 4 & .83 & 0.019 \\
\hline Fever $>100.0^{\circ} \mathrm{F}$ & 20 & 18 & .48 & 0.051 \\
\hline Physician visit within 3 days of infection onset & 36 & 32 & .30 & 0.091 \\
\hline
\end{tabular}

$\mathrm{SD}=$ standard deviation 
Table 3

Medicare Expenditures per Case of Infection According to Triage Group

\begin{tabular}{|c|c|c|c|}
\hline \multirow[b]{2}{*}{ Expenditure } & Hospital Triage & Nursing Home Triage & \multirow[t]{2}{*}{$\begin{array}{l}\text { Hospital:Nursing Home Expenditure Ratio (95\% } \\
\text { Confidence Interval) }\end{array}$} \\
\hline & \multicolumn{2}{|c|}{$\$$, Mean \pm Standard Deviation } & \\
\hline Total & $5,202 \pm 7,325$ & $996 \pm 2,475$ & $6.07(4.30-8.58)^{\dagger}$ \\
\hline Inpatient & $4,225 \pm 7,006$ & $597 \pm 2,156$ & $8.17(5.04-13.24)^{\dagger}$ \\
\hline Physician visits & $623 \pm 1,109$ & $141 \pm 391$ & $5.44(3.92-7.56)^{\dagger}$ \\
\hline Other provider visits & $394 \pm 390$ & $140 \pm 231$ & $3.22(2.62-3.95)^{\dagger}$ \\
\hline Nursing home skilled nursing days & $239 \pm 660$ & $92 \pm 458$ & $5.21(2.49-10.90)^{\dagger}$ \\
\hline Emergency department & $187 \pm 182$ & $26 \pm 90$ & $7.74(4.85-12.34)^{\dagger}$ \\
\hline Radiology & $49 \pm 120$ & $13 \pm 34$ & $3.76(2.36-5.98)^{\dagger}$ \\
\hline Laboratory & $40 \pm 60$ & $26 \pm 45$ & $1.70(1.26-2.31)^{\dagger}$ \\
\hline
\end{tabular}

